\title{
The Morphological and Immunohistochemical Features of a Pedunculated Vulvar Angiomyofibroblastoma: A Case with Review of Literature
}

\author{
Stephanie Purnell ${ }^{1}$, Patrick Lam ${ }^{1}$, Dynell Pinder ${ }^{1}$, Sarah Mohamedaly ${ }^{1}$, Christina \\ Lipscombe $^{2}$, Dr. Tammey Naab ${ }^{3}$, Dr. Bonnie Davis ${ }^{4}$, Dr. Pamela Coleman ${ }^{1}$ \\ ${ }^{I}$ Division of Urology, Howard University Hospital, Washington, DC, USA \\ ${ }^{2}$ Philadelphia College of Osteopathic Medicine, Philadelphia, PA, USA \\ ${ }^{3}$ Department of Pathology, Howard University Hospital, Washington, DC, USA \\ ${ }^{4}$ Department of Radiology, Howard University Hospital, Washington, DC, USA
}

\begin{abstract}
Angiomyofibroblastoma (AMF) is a rare and benign soft tissue tumor that presents in the vulvovaginal area in women. Numerous entities such as Bartholin's cysts, aggressive angiomyxoma, cellular angiofibroma, fibroepithelial stromal polyps, and superficial myofibroblastoma can also develop in the female genital region and mimic AMF; distinguishing between these lesions can be difficult due to their morphological similarities. Among the tumors mentioned, histological similarities add strain to AMF diagnosis. Furthermore, the immunohistochemical variability that exists within each discrete tumor category makes differentiation arduous. While challenging, it is necessary to diagnose these lesions accurately and hastily as the prognosis for each tumor differs and has influence on treatment measures.
\end{abstract}

Keywords - Angiomyofibroblastoma, benign mesenchymal tumor, immunohistochemistry, morphology, vulvar tumor

\section{INTRODUCTION}

Distinguishing between the various soft tissue neoplasms of the vulvovaginal region can be difficult due to the morphological and histological similarities between and the immunohistochemical variability within each tumor type [1]. The differentiation of these vulvar lesions has important prognostic implications as some behave aggressively making rapid intraoperative pathological diagnosis necessary. Here we present an unusual case of the rare tumor angiomyofibroblastma (AMF). We would like to emphasize that although AMF typically presents as a small, painless, and slow growing mass, these lesions can be large, painful, and/or pedunculated [2-3].

\section{CASE PRESENTATION}

A 60 year old African American woman presented to the urology clinic complaining of frequency of urination, urgency, and dysuria, as well as mild pain when wiping her vagina for ten days duration. Upon physical examination, it was noted that her external genitalia showed vulvar atrophy, swelling of the right labia major, a palpable mobile rubbery lesion of the right labia majora (Fig. 1), and an absent cervix and uterus. No other lesions were visible. She was diagnosed with urinary tract infection (UTI), prescribed antibiotics, and scheduled for a CT scan of her abdomen and pelvis with and without contrast. The CT revealed heterogeneously enhancing right sided labial mass about $5 \mathrm{~cm}$ in diameter and no other abnormal findings (Fig. 2). As a result of this finding, the patient was scheduled for mass excision (Fig. 3). A frozen section of the mass was sent to pathology for

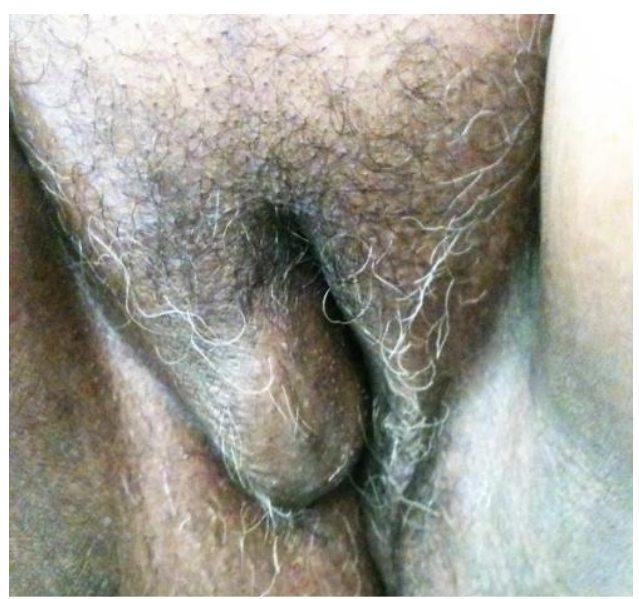

Figure 1: Swelling of right labia with mass. intraoperative diagnosis. 

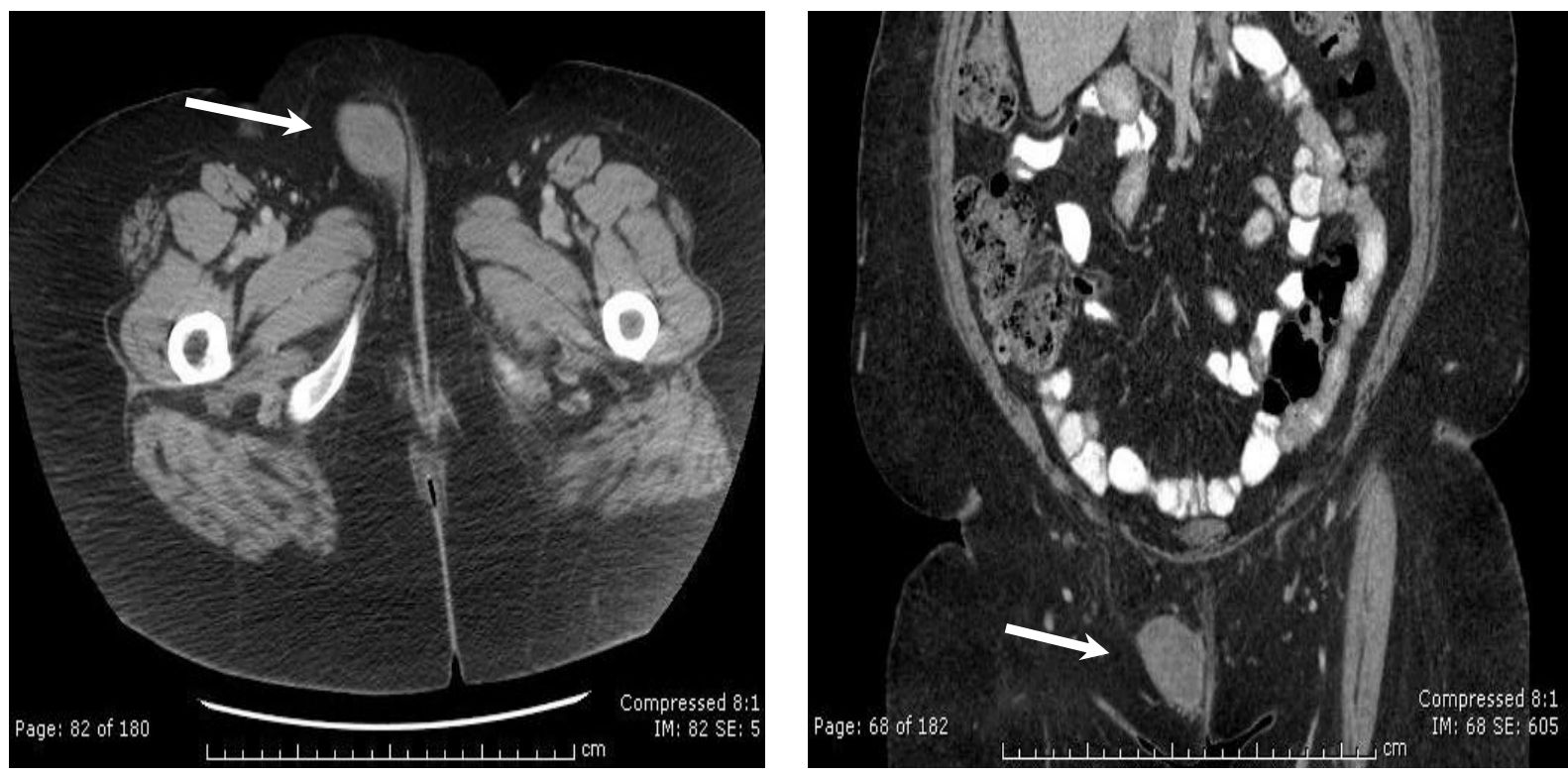

Figure 2: (A) Transverse Computed Topography (CT) scan of abdomen and pelvis with $5 \mathrm{~cm}$ right sided labial mass (arrow). (B) Coronal CT scan of abdomen and pelvis right with heterogeneously enhancing sided labial mass (arrow).
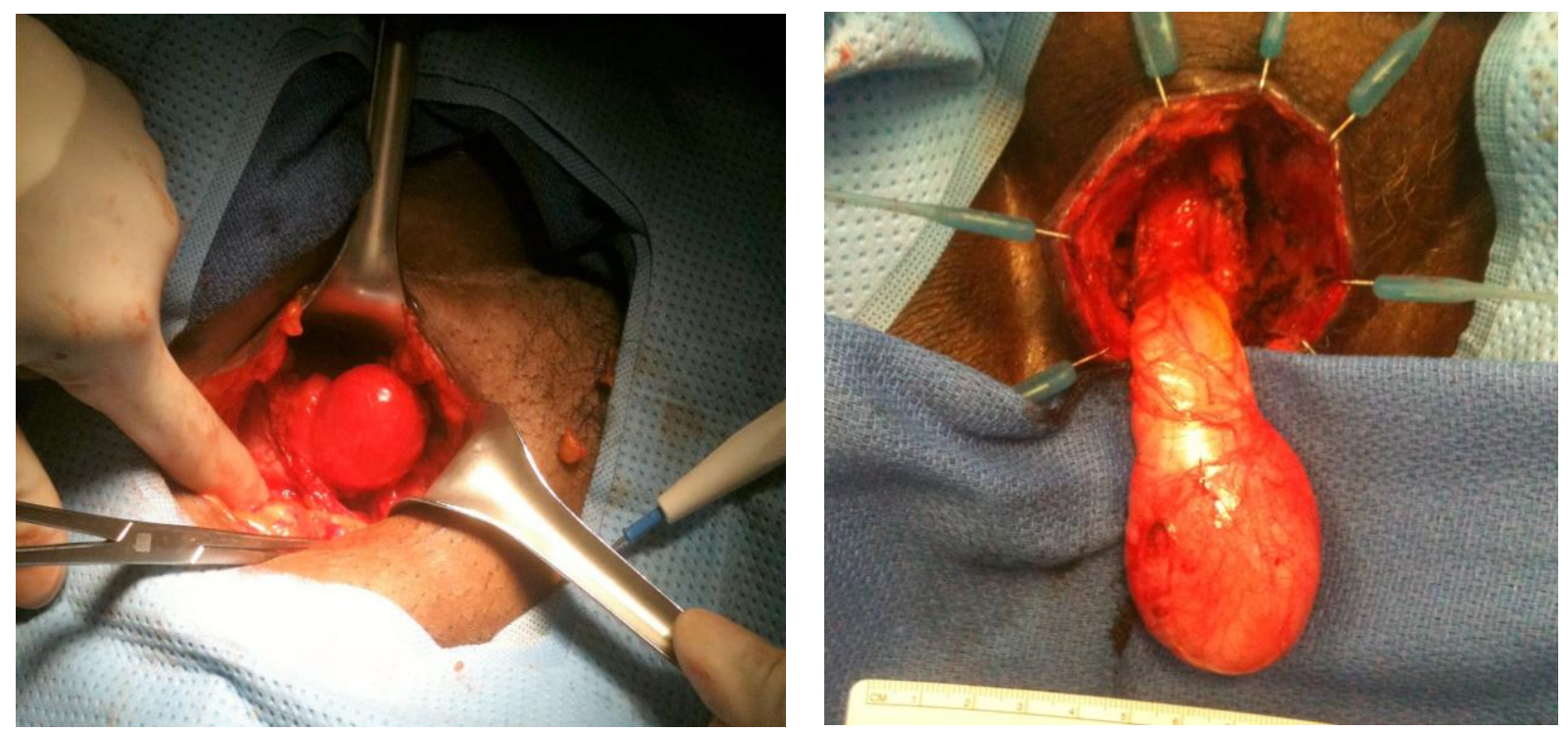

Figure 3: (A) Excision of right labial mass. (B) Pedunculated right labial mass.

The pathologist described the tumor as a benign well circumscribed pseudoencapsulated pedunculated mass containing numerous vessels surrounded by clusters of epitheloid cells that merge with the muscular walls of those vessels (Fig. 4-6). The spindled, fuisiform, and epitheloid cells were arranged in short fascicles with focal palisading between prominent thin-walled vasculature (Fig. 7). Immunohistochemically, these epitheloid cells expressed desmin, vimentin, CD34, and estrogen receptor protein but lacked expression of smooth muscle actin (Fig. 8-9) Considering these features, a diagnosis of angiomyofibroblastoma was made, malignancy was excluded, and the local excision was determined to be sufficient having clear margins. 


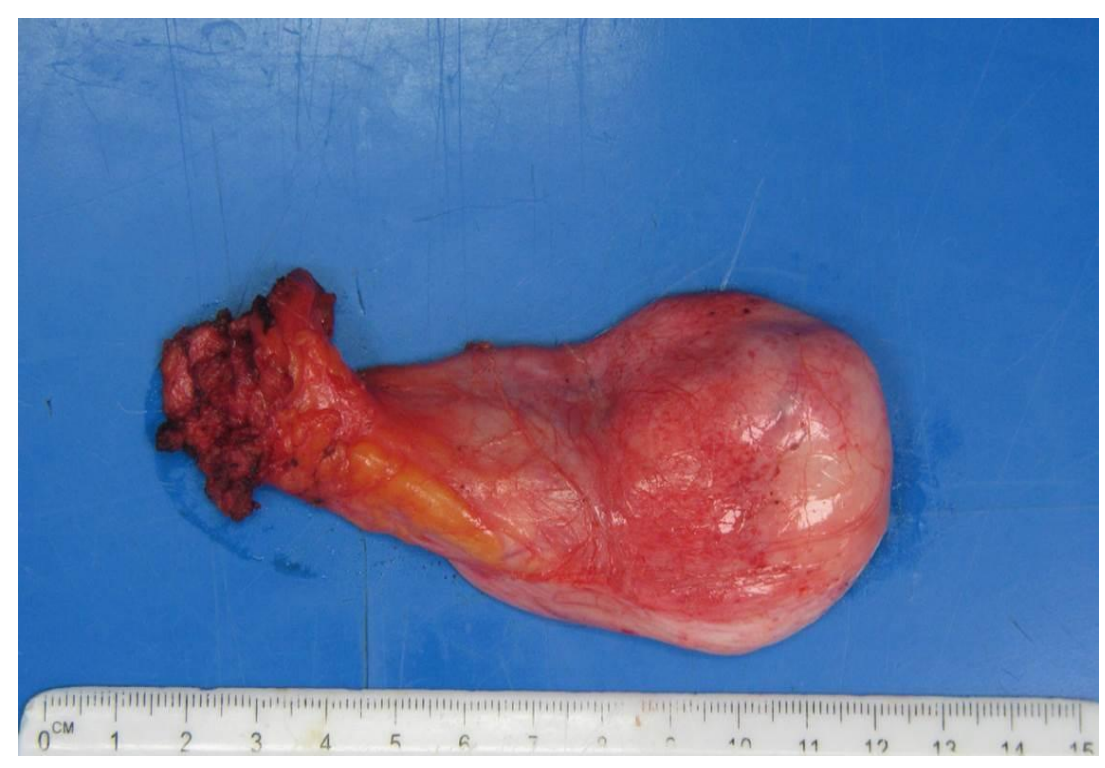

Figure 4: Gross image of the well-circumscribed, pseudoencapsulated pedunculated polypoid mass measuring $11.0 \times 4.2 \times 2.2 \mathrm{~cm}$ in greatest dimensions.

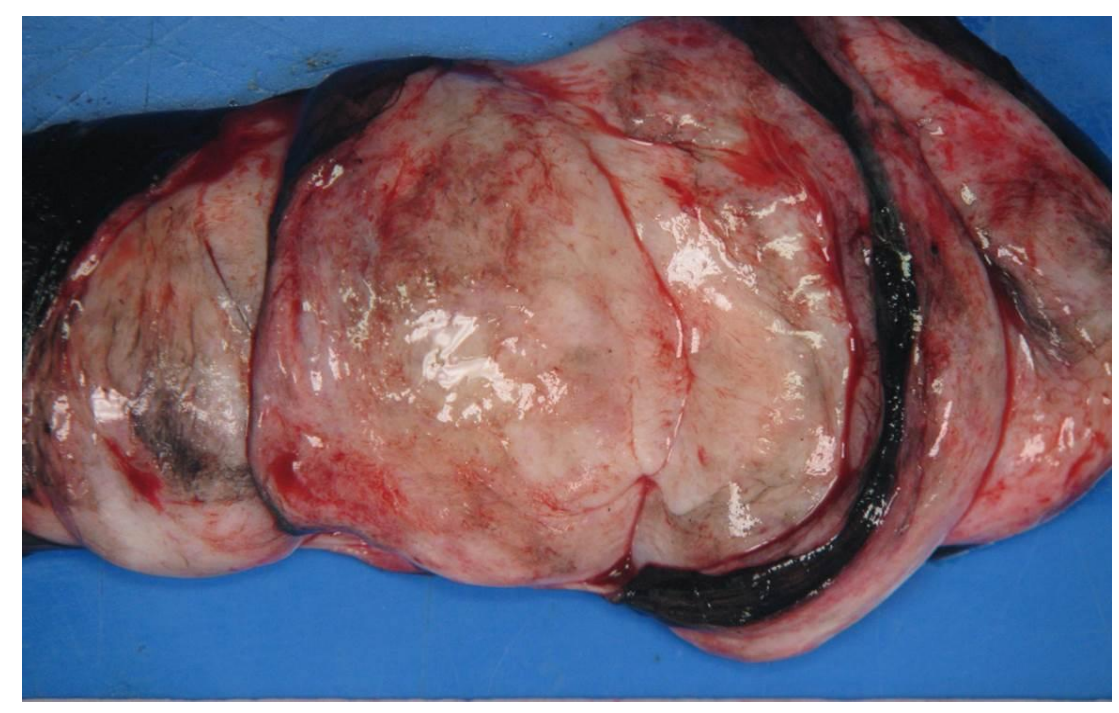

Figure 5: Gross image of the pedunculated mass. Cut surfaces are gelatinous, glistening and bulging.

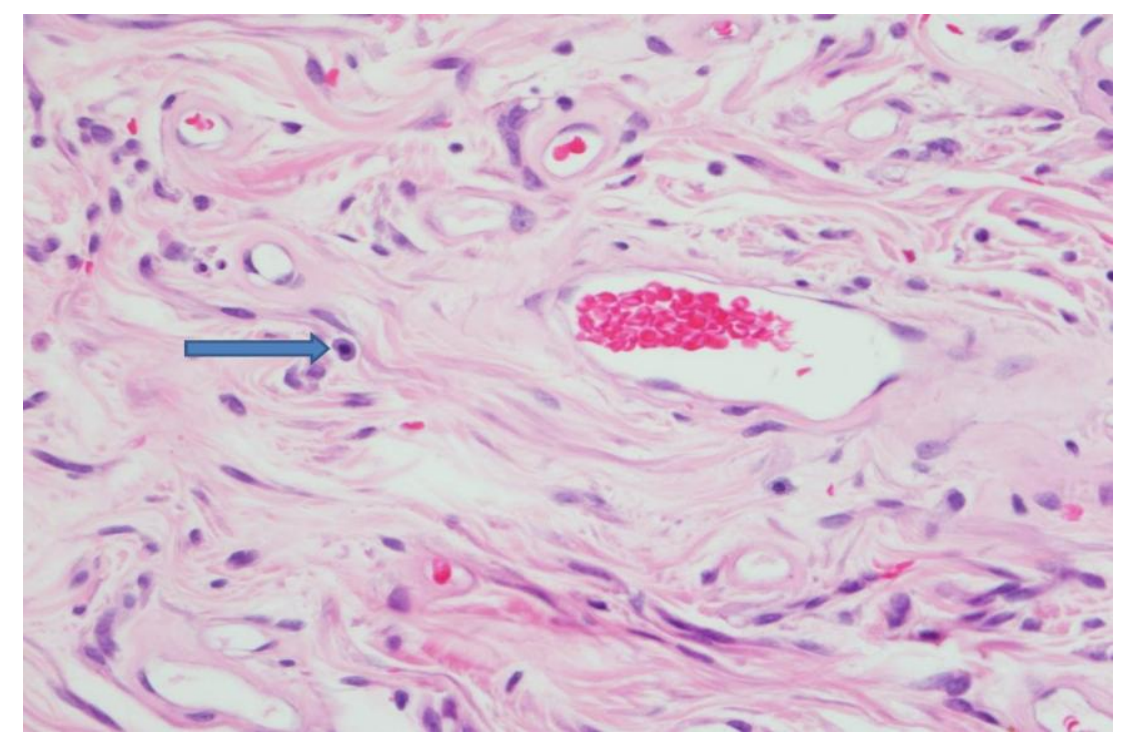

Figure 6: Cellular bland spindle and epithelioid cell proliferation in short fascicles arranged around evenly distributed thin-walled capillaries and venules with mast cell (arrow) in a pseudovascular space $(\mathrm{H} \& \mathrm{E}$ stain 400X). 


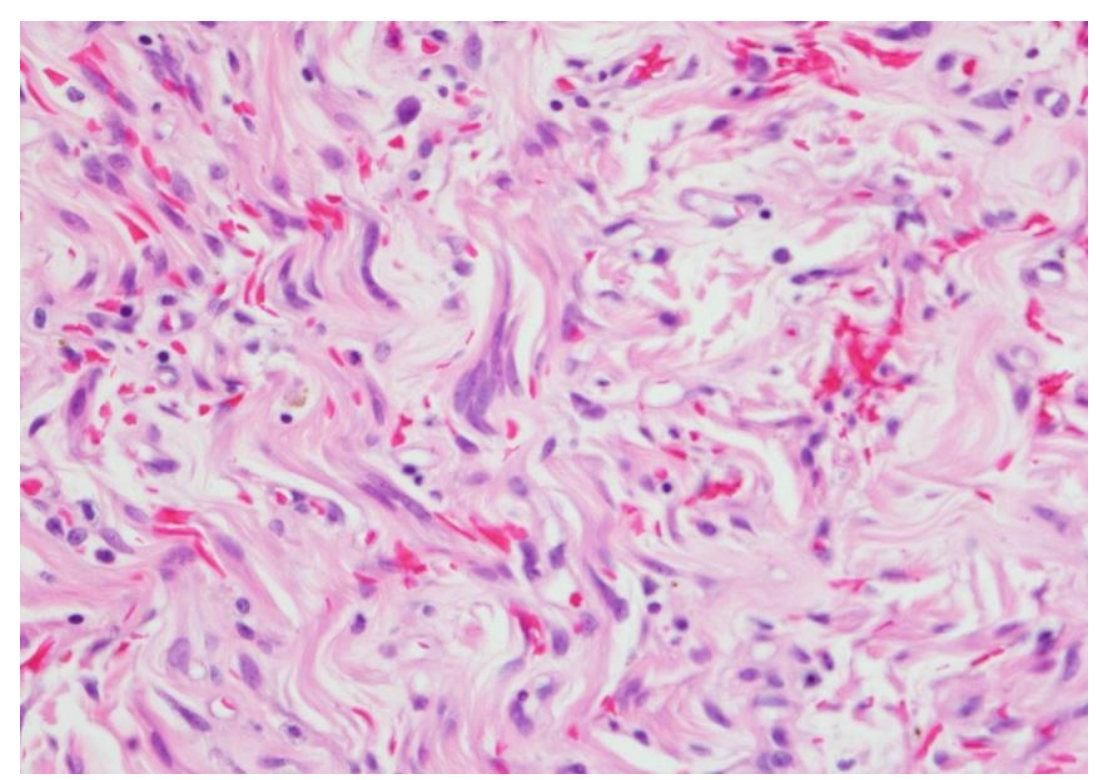

Figure 7: Spindled, fusiform, and epithelioid cells arranged in short fascicles with focal palisading between prominent thin-walled vasculature (H\&E stain 400X).
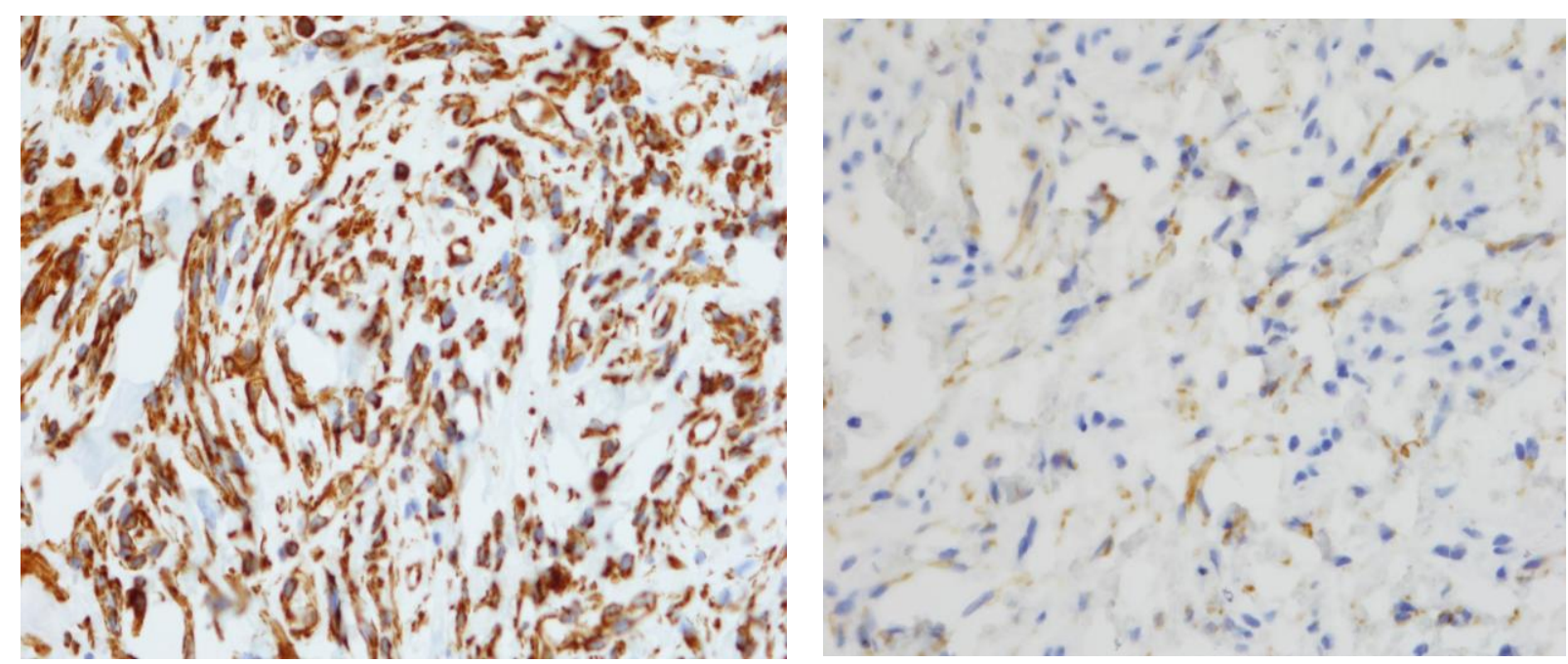

Figure 8: (A) Strong, diffuse cytoplasmic expression of vimentin in spindled and epithelioid cell proliferation (400X). (B) Patchy cytoplasmic expression of desmin in spindled and fusiform cells (400X).
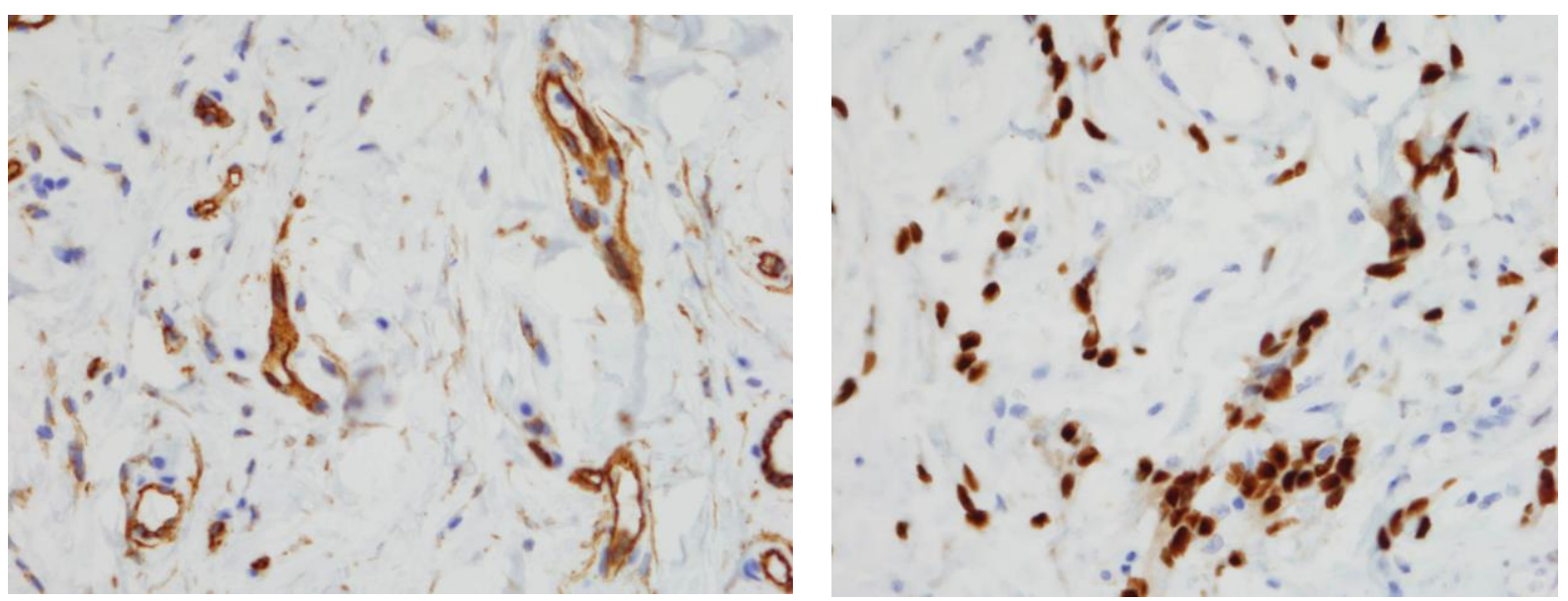

Figure 9: (A) CD34 cytoplasmic expression confined to prominent thin-walled vessels (400X). (B) Strong, diffuse nuclear ER expression in spindled and epithelioid cells (400X). 


\subsection{Investigations}

\section{DISCUSSION}

Intraoperative pathological diagnosis with microscopy and immunohistocemical staining of tissue from the mass was necessary to determine the tumor type.

\subsection{Differential Diagnosis}

The numerous types of vulvar tumors make a diagnosis of AMF difficult. Thus, a rapid intraoperative pathological diagnosis should be made keeping in mind AAM, cellular angiofibroma (CA), fibroepithelial stromal polyp (FSP), and superficial angiomyxoma (SA), all of which are comparable vulvar lesions. Table 1 below describes their morphology and immunohistochemistry [5-8].

Table 1. Morphologic and Immuunohistochemical Characteristics Of Five Vulvar Lesions.

\begin{tabular}{|c|c|c|c|c|c|}
\hline Tumor & AMF & $\mathbf{A A M}$ & CA & FSP & SA \\
\hline General Size & $<5 \mathrm{~cm}$ & $>10 \mathrm{~cm}$ & $<6 \mathrm{~cm}$ & $<5 \mathrm{~cm}$ & $<5 \mathrm{~cm}$ \\
\hline Morphology & $\begin{array}{l}\text { Well } \\
\text { circumscribed, } \\
\text { sessile, rarely } \\
\text { exophytic }\end{array}$ & $\begin{array}{l}\text { Poorly } \\
\text { circumscribed, } \\
\text { subcutaneous, } \\
\text { invasive }\end{array}$ & $\begin{array}{l}\text { Well } \\
\text { circumscribed }\end{array}$ & $\begin{array}{l}\text { Poorly } \\
\text { circumscribed, } \\
\text { exophytic }\end{array}$ & $\begin{array}{l}\text { Poorly } \\
\text { circumscribed }\end{array}$ \\
\hline Cellularity & $\begin{array}{l}\text { - Hypo and } \\
\text { hypercellular } \\
\text { areas } \\
\text { - Myxoid } \\
\text { stroma Large } \\
\text { epithelioid } \\
\text { and/or spindle } \\
\text { cells } \\
\text { - Rarely fatty } \\
\end{array}$ & $\begin{array}{l}\text { - Hypocellular } \\
\text { - Myxoid } \\
\text { stroma with } \\
\text { entrapped } \\
\text { smooth muscle } \\
\text { fibers }\end{array}$ & $\begin{array}{l}\text { - Spindle cells } \\
\text { - Rarely fatty }\end{array}$ & $\begin{array}{l}\text { - Bizarre } \\
\text { stromal cells } \\
\text { - Multi- } \\
\text { nucleated giant } \\
\text { cells }\end{array}$ & $\begin{array}{l}\text { - Stromal } \\
\text { neutrophils }\end{array}$ \\
\hline Vascularity & $\begin{array}{l}\text { - Numerous } \\
\text { vessels } \\
\text { - Thin } \\
\text { capillaries and } \\
\text { venules }\end{array}$ & $\begin{array}{l}\text { - Small to large } \\
\text { vessels } \\
\text { - Thick walls }\end{array}$ & $\begin{array}{l}\text { - Hyalinized } \\
\text { round vessels } \\
\text { - Small to large } \\
\text { - Thick walls }\end{array}$ & - & $\begin{array}{l}\text { - Long vessels } \\
\text { - Small vessels } \\
\text { - Thin walls }\end{array}$ \\
\hline Desmin & + & + & $\begin{array}{l}\text { variable }(+ \text { in } \\
10 \% \text { of cases })\end{array}$ & variable & variable \\
\hline Vimentin & + & + & + & - & + \\
\hline ER/PR & + & variable & variable & variable & - \\
\hline CD34 & $+50 \%$ of cases & - & - & + & - \\
\hline Treatment & Local excision & Wide excision & Local excision & Local excision & Local excision \\
\hline
\end{tabular}

These tumors can exhibit variability in their immunophenotypes, but generally the above observations have been made and are standard for diagnosis [6].

\subsection{Treatment}

Based on intraoperative pathological diagnosis, the treatment for our patient's tumor was local excision. The margins were clear, thus no further excision was necessary. Success of treatment is assessed by follow-up and the absence of tumor recurrence.

\subsection{Outcome \& Follow-Up}

The patient has been in follow-up for two years with a clinical examination every six months with no evidence of mass recurrence; her treatment was successful. 


\section{CONCLUSION}

Angiomyfibroblastoma, which was first described by Fletcher et al in 1992, is a rare, small, and benign mesenchymal tumor with a predilection for the vulvovaginal region in women [1-9]. Clinically, AMF can be confused with aBartholin's cysts as well as other soft tissue neoplasms such as aggressive angiomyxoma (AAM) [1-4]. Based on histological and immunolopathological characteristics, pathologists are able to differentiate AMF from other entities. Differentiation is indespensible as some tumors, like AAM, exhibit aggressive behavior and are treated differently that benign tumors; the prognostic implications each diagnosis make proper identification and treatment crucial.

Morphologically and histologically, AMF is customarily non-pedunculated, has sharply demarcated boarders, maintains a predominantly perivascular distribution, and contains large epithelial cells and myxoid stroma rarely occurring with fat cells [5-6]. Our patient's tumor was pedunculated which as previously stated is unusual. Her presentation helps support the idea that it is vital to think divergently and creatively when confronted with vulvar lesions. The prevalence and incidence of pedunculated vulvar AMF is unknown, but there have been at least six reported cases in English literature in recent years of which makes our patient's case at least the seventh [3-4]. AMF also has a higher cellularity and more numerous blood vessels than AAM, its major neoplastic contender [2,4-5].

Immunohistochemically, AMF cells are typically reactive for desmin, vimentin, estrogen receptors and progesterone receptors, while half of cases will stain positive for CD34 [5-6]. AMF also generally stains negative for cytokeratin, muscle-specific actin, smooth muscle actin, and S-100 protein, but there have been cases of AMF reported that were actin positive, as well as desmin negative [4-5]. Given the variable immunostaining patterns that exist, the medical community would benefit from the development of other approaches to better characterize and diagnose AMF. Until then, immunohistochemical staining is indispensable in the work-up and diagnosis of AMF and other vulvovaginal tumors.

This report aims to emphasize that although AMF tends to be a sessile lesion, it can also present in a non-sessile form; one must keep angiomyofibroblastoma in mind when encountering a pedunculated lesion. We also want to highlight that after excluding a Batholin's cyst, the presence of a pedunculated mass warrants an investigation of mesenchymal tumors including, but not only, angiomyofibroblastoma and aggressive angiomyxoma. The treatment of choice for the former being local surgical excision with clear margins, which is resolutive as established by this case and others reported in the literature

\section{REFERENCES}

[1] Fletcher C, Tsang W, Fisher C, Lee K, Chan J. Angiomyofibroblastoma of the Vulva. The American Journal of Surgical Pathology. 1992;16(4):373-382.

[2] Magro, G, Salvatorelli, L, Vecchio, G, Caltabiano, R. Lipomatous angiomyofibroblastoma of the vulva: diagnostic and histogenetic considerations. Pathologica. 2014;106(4):322-6.

[3] Giannella, L., Costantini, M., Mfuta, K., Cavazza, A., Cerami, L., Gardini, G., \& Boselli, F. Pedunculated Angiomyofibroblastoma of the Vulva: Case Report and Review of the Literature. Case Reports In Medicine. 2011;2011:1-4. http://dx.doi.org/10.1155/2011/893261.

[4] Omori M, Toyoda H, Hirai T, Ogino T, Okada S. Angiomyofibroblastoma of the vulva: a large pedunculated mass formation. Acta Medica Okayama. 2006;60(4):237-242.

[5] Kumarapeli A, Paczos T, Azabdaftari G. Morphological and Immunohistochemical Features of Angiomyofibroblastoma: A Case Report with Review of the Literature. N A J Med Sci. 2011;4(2):100. 
[6] Nielsen G, Young R. Mesenchymal Tumors and Tumor-Like Lesions of the Female Genital Tract: A Selective Review with Emphasis on Recently Described Entities. International Journal of Gynecological Pathology. 2001;20(2):105-127.

[7] Kempson R, Rouse R. Angiomyofibroblastoma - Surgical Pathology Criteria - Stanford University School of Medicine [Internet]. Surgpathcriteria.stanford.edu. 2015 [cited 2 July 2015]. Available from: http://surgpathcriteria.stanford.edu/softmisc/angiomyofibroblastoma/printable.ht $\underline{\underline{m l}}$

[8] McCluggage W. Aggressive angiomyxoma of pelvic parts exhibits oestrogen and progesterone receptor positivity. Journal of Clinical Pathology. 2000;53(8):603-605.

[9] Ganesan R, McCluggage W, Hirschowitz L, Rollason T. Superficial myofibroblastoma of the lower female genital tract: report of a series including tumours with a vulval location. Histopathology. 2005;46(2):137-143. 